Int. J. Electrochem. Sci., 15 (2020) 10550 - 10569

\title{
Influences of Duty Cycle and Pulse Frequency on Properties of Ni-SiC Nanocomposites fabricated by Pulse Electrodeposition
}

\author{
Haijun Liu ${ }^{1}$, Hui Wang ${ }^{1, *}$,Weijun Ying ${ }^{1}$, Wenqing Liu ${ }^{2}$, Yong Wang $^{2}$, Qiang Li $^{2}$ \\ ${ }^{1}$ College of Engineering and Technology, Jiyang College of Zhejiang Agriculture \& Forestry \\ University, Zhuji, 311800, China; \\ ${ }^{2}$ College of Mechanical Science and Engineering, Northeast Petroleum University, Daqing 163318, \\ China \\ *E-mail: today2020529@126.com, 20168009@zafu.edu.cn
}

doi: $10.20964 / 2020.10 .33$

Received: 30 May 2020 / Accepted: 27 July 2020 / Published: 31 August 2020

\begin{abstract}
$\mathrm{Ni}$-SiC nanocomposites (NCs) were fabricated using pulse current electrodeposition (PCED) in this article. Influences of PCED frequency and duty cycle on morphology, structure, wear and corrosion behavior of the resulting NCs were thoroughly analyzed using a variety of instrumental techniques such scanning electron and transmission electron microscopies (SEM and TEM, respectively), X-ray diffraction (XRD) as well as wear, corrosion and nanoindentation tests. The results illustrated that the surface of the Ni-SiC NC obtained at the $20 \%$ duty cycle contained small Ni grains with smooth, uniform, and fine microstructure. When the coatings were prepared in the $25-50 \mathrm{~Hz}$ pulse frequency range, SiC NPs were homogeneously dispersed in the coating, and the resulting NCs were uniform, compact and contained fine grains. Among NCs fabricated at different pulse frequencies and $20 \%$ duty cycle, Ni-SiC coatings deposited at $50 \mathrm{~Hz}$ showed the highest microhardness value (equal to 911.9 $\mathrm{Hv}$ ). Wear weight loss of the Ni-SiC NC prepared at $20 \%$ duty cycle was only $18.1 \mathrm{mg}$, which indicates an excellent wear resistance. In addition, EIS of our Ni-SiC NCs deposited at $50 \mathrm{~Hz}$ pulse frequency and 20\% duty cycle showed the highest impedance, which implies the best corrosion resistance. The result can be applied to the micro precision transmission mechanism for manufacturing various small electric valves and actuators in engine compartments.
\end{abstract}

Keywords: Ni-SiC NCs; duty cycle; pulse frequency; structure; wear resistance; corrosion resistance

\section{$\underline{\text { FULL TEXT }}$}

(C) 2020 The Authors. Published by ESG (www.electrochemsci.org). This article is an open access article distributed under the terms and conditions of the Creative Commons Attribution license (http://creativecommons.org/licenses/by/4.0/). 